\title{
Tuberculous Otomastoiditis
}

\author{
Acosta Boett Ligia ${ }^{3}$, Marian Fuentes ${ }^{1}$, Bastidas Yanet $^{2}$, Arrieta Noraima ${ }^{2}$, Rodríguez Olira ${ }^{1}$, Rivas Carlos ${ }^{1}$ and $^{2}$ \\ Delgado Beatriz ${ }^{1}$ \\ ${ }^{1}$ Residente del Postgrado de Otorrinolaringología. Hospital de Niños “Dr. José Manuel de los Ríos", South America
}

${ }^{2}$ Adjunto del Servicio de Otorrinolaringología. Hospital de Niños “Dr. José Manuel de los Ríos”, South America

${ }_{3}^{3}$ Jefe de Servicio de Otorrinolaringología. Hospital de Niños “Dr. José Manuel de los Ríos", South America

Submission: February 16, 2017; Published: February 28, 2017

*Corresponding author: Acosta Boett Ligia, Jefe de Servicio de Otorrinolaringología. Hospital de Niños “Dr. José Manuel de los Ríos”,

Vicepresidenta de la Junta Directiva SVORL, Venezuela, South America, Email: ligiaorl2@gmail.com

\section{Abstract}

Introduction: Otomastoiditis tuberculosis is a very rare clinical presentation of TB ranging from $0.05 \%$ to $0.9 \%$. Clinical triad includes painless serous otorrhea, perforated eardrum and facial paralysis. It begins slowly and insidiously and is associated with bacterial super infection and hearing loss. The diagnosis requires sputum smear, cultivation of biological material, intradermal Mantoux reaction and chest radiography.

Clinical Case: Preschool female 4 years old, resident in Miranda, current disease with 26 days of duration, characterized by otodynia, purulent, green and odorless left otorrhea and hyperthermia. Goes to doctors who suggest oral antibiotics with Amoxicilina/Ac. Clavulanate, Cefadroxil and topical antibiotics like Ciprofloxacin. Symptoms persist so she receives parenteral ceftriaxone also unsuccessfully so she is hospitalized.

Physical Exam: retroauricular increased volume, soft, without signs of styes, left stenotic ear canal, hyperemic, abundant green odorless otorrhea, not evaluable tympanic membrane. Laterocervical left lymphadenopathy, mobile, painless, of $1.5 \mathrm{cms}$. Patient receives parenteral antibiotic therapy with no improvement.

a. Functional Study: moderate left conductive hearing loss.

b. Computed Tomography middle ear and mastoid: isodensity, occupying left middle ear and mastoid with erosion of the mastoid cortex. Tympanoplasty with mastoidectomy and left open biopsy is performed.

c. Anatomopathological report: Chronic granulomatous Otomastoiditis. PPD is done: positive (18 $\mathrm{mm})$, anti TB treatment is initiated: Isoniazid, Rifampicin, Piperazinamida and ethambutol.

Conclusion: suspect tubercular etiology in cases of painless otomastoiditis that do not respond to the usual antibiotic treatment. The PPD as a valuable tool should be used routinely for early diagnosis and lower risk of complications.

Keywords: Otomastoiditis; Tuberculous

\section{Introduction}

Acute and Chronic Otitis Media; Constitute a public health problem on a global scale, resulting in high morbidity, medical consultations, prescriptions and sequelae [1]. In the pediatric population otitis media is a frequent reason for consultation [2]. In Venezuela, it is among the first causes of consultation and occupies the thirteenth position within the group of notifiable diseases [1]. About $84 \%$ of children have at least one episode of otitis media during childhood [2]. About $40 \%$ of these will continue with recurrent chronic suppurative otitis media [1].
Diseases of the ear and mastoid process are grouped into 4 pathologies: Otitis Externa, Acute Otitis Media in children under 5 years, Acute Otitis Media in children over 5 years, and Otitis Media Chronic [1]. As mentioned earlier, the volume of annual consultations for otitis is very high. Most of these visits are for acute otitis media, with a daily average of 648 visits. However, it should be noted that Otitis Media Chronic with only an average of 28 consultations per day has greater complications and is responsible for a high percentage of school and work absenteeism; As well as hearing loss [1]. 
As for the sequels; The group that studied the burden of Acute Otitis Media around the world, estimates hearing loss less than $25 \mathrm{~dB}$ as the most important. For our region, this study registers between 4 and 6 cases per 10,000, reaching a figure of 14,000 hearing-impaired patients per year due to this etiology [3]. Otitis Media is defined as the sudden appearance of signs and symptoms of infection of the middle ear mucosa [1,2]. Depending on the evolution time, they are classified as:

a) Acute Otitis Media: up to 3 weeks of evolution [1].

b) Subacute Otitis Media: 3 weeks to 3 months duration [1].

c) Otitis Media Chronic: more than 3 months of Evolution [1].

When the inflammatory process of the middle ear mucosa extends to the underlying bone, otomastoiditis occurs. Osteitis affects the cortical of the mastoid and causes signs of flogosis in the retroauricular region, with the installation of a cellulite, phlegmon or abscess. Otomastoiditis can be a complication of otitis media or constitute the first manifestation of ear disease [1]. In general, the microorganisms involved are Streptococcus pneumoniae, Streptococcus pyogenes, Staphylococcus aureus, Haemophilus influenzae and Pseudomonas aeruginosa [1]. Otomastoiditis requires hospitalization, supportive measures and parenteral antibiotic therapy to avoid the risk of intracranial complications, such as meningitis, sigmoid sinus thrombosis and brain abscess [1].

The selection of antibiotic therapy depends on the severity of the case and the conditions of the patient. Empirical treatment with third generation cephalosporins such as cefotaxime, ceftriaxone, is recommended. In case of torpid evolution or isolation of resistant germs, glycopeptides such as vancomycin or teicoplanin are used [1]. In those cases where the infectious process exceeds 3 months of evolution, we can refer to a chronic otitis media (chronic otomastoiditis). In Otitis Media Chronic the most frequent manifestations are recurrent otorrhea, tympanic perforation and hearing loss. The alteration in anatomical structures and physiology varies widely from one patient to another [1].

The etiology of chronic infection is polymicrobial. The germs of greatest growth in the cultures are: Pseudomona aeruginosa, Proteus mirabilis, Staphylococcus aureus, Streptococcus pyogenes, Escherichia coli, Klebsiellas spp, Anaerobic Germs: Peptostreptococcus spp, Prevotella, Bacteroides fragilis, Propionibacterium species. Other: Mycobacterium tuberculosis, Nocardia, Aspergillus [1]. Chronic otitis media are classified as:

a) Chronic otitis media Cholesteatomatous

b) Chronic otitis media Cholesteatomatous:

c) Otitis media suppurative

i. Otitis media effusion

\section{ii. Chronic atelectasic otitis media}

iii. Adhesive otitis media

The otitis media with effusion is considered a non-infectious disease, however in recent studies the presence of germs is reported, evidenced by PCR in the effusion, Haemophylus influenzae being the dominant pathogen in $51 \%$ of the cases [1]. In patients with chronic non-cholesteatomatous suppurative otitis, ear cleansing, application of antiseptic solutions and topical antibiotics (5\% iodinated solutions and $0.2 \%$ ciprofloxacincontaining drops) have shown effectiveness in drying the ear; Even more than the use of systemic antibiotic therapy. In children with chronic exudative otomastoiditis, intravenous treatment with: third generation cephalosporins Antiepileptic (ceftazidime) or fourth generation (cefepime) with clindamycin, carbapenems (imipenem or meropenem), piperacillin / tazobactam. In adults, oral therapy with ciprofloxacin with or without clindamycin may be administered [1].

The time of medical treatment oscillates between 2 and 3 weeks. Once the infection is controlled, patients must undergo surgical treatment to repair the sequelae and avoid further complications [1]. Patients with chronic otitis media with cholesteatoma require surgical treatment. Cholesteatoma is an avascular pseudotumor, with great lytic capacity, which must be resected as soon as it is identified. The benefit of topical and systemic antibiotics is relatively poor and is recommended only to improve local conditions prior to surgery. In complicated cases, the patient requires hospitalization and parenteral treatment with third or fourth generation cephalosporins. In some cases it may be necessary to associate vancomycin or clindamycin [1].

Regarding tuberculosis (TB), it is important to note that it is still a public health problem in Venezuela and a diagnosis that must be considered during daily medical practice in the country's hospitals. It is one of the earliest human diseases to be known; Although its age is estimated between 15,000 and 20,000 years, it is accepted that the microorganism that originated it evolved from other more primitive microorganisms within the genus Mycobacterium itself [4].

International organizations such as the World Health Organization (WHO), the United Nations (UN), the Pan American Health Organization (PAHO) and the International Union Against Tuberculosis and Respiratory Diseases (UICTER) have recognized tuberculosis (TB) as a threat of suffering and death in several countries of the world. Most recent international statistics and latest publications. A third of the world's population is affected by it, and that 9 million new cases and 3 million deaths are recorded every year because of it. Latin America does not escape its havoc; And in our country, along with other pathological entities, it is considered a reemerging disease that must be diagnosed and treated early [5].

Tuberculosis is an infectious and opportunistic disease that primarily affects individuals of lower socioeconomic status, as 
well as those with compromised immune systems due to age (children or the elderly), infections (HIV) or treatment with modulators Immune system (organ transplantation, collagen disease) [5]. Mycobacterium tuberculosis is the most frequently responsible bacillus of tuberculosis in humans, although other bacilli of the $\mathrm{M}$ tuberculosis complex (bovis, africanum, microti) have also been reported as causative agents. The most common form of presentation of the disease is Pulmonary Tuberculosis. However, this agent can affect other organs of the economy through its extrapulmonary manifestations $[5,6]$.

The extrapulmonary form accounts for 15 to $25 \%$ of all cases of the disease. Its location is very diverse, but occurs less frequently in some areas (meninges, otorhinolaryngological area, abdomen, pelvis) than in others (pleura, kidney, bone, brain). Due to the lack of clinical manifestations characteristic of the pulmonary form and / or antecedents of the same, the extrapulmonary form is frequently confused with other pathologies leading to delays and costly errors in the diagnosis and definitive treatment [5]. In this regard, a clinical case corresponding to one of the infrequent expressions of extrapulmonary tuberculosis in the otorhinolaryngological area, such as that corresponding to aural tuberculosis, will be presented.

\section{Clinical Case}

\section{Current disease}

Female pre-school, 4 years old, from Miranda, with current disease of 26 days, characterized by otodynia, left green otorrhea, purulent, non-fetid and hyperthermia. It refers to clinicians who indicate oral antibiotic therapy with Amoxicillin / Ac. Clavulanic, Cefadroxil, topical antibiotics such as Ciprofloxacin. Persist symptomatology, receives ceftriaxone parenteral without response so it is entered. Prenatal and Obstetric Antecedents: Product of 29 years old mother, I gesta, poorly controlled pregnancy, obtained at 38 weeks' gestation by instrumental delivery (forceps) does not specify cause.

\section{Neonatal Background}

Breathe and cry at birth, NAR: $3 \mathrm{~kg}$ TAN: $52 \mathrm{~cm}$, Hospitalized in neonatal area for 72 hours (no diagnosis required).

\section{Feeding} diet.

Mixed breastfeeding from birth, currently included in family

\section{Personal background}

Refers to hospitalization for 15 days; At 7 months of age, due to infection of the respiratory tract: Pneumonia.

\section{Family background}

Paternal Line: Father 27 years alive, APS. Rest Unknown.

Mother Line: Mother 33 years old, APS. Abuela Materna 57 years alive, Arterial Hypertension. Uncle Materno 36 years alive, T.B.C in 2013 treated (no report).

\section{Immunizations}

Complete scheme for the age according to the mother (No card holder).

\section{Functional exam}

Ear: Otorrhea purulent left, abundant, greenish, non-fetid, and ipsilateral otodynia.

\section{Physical exam (11/26/14)}

a) FC: 87 lpm FR: 18 rpm Weight: $14.8 \mathrm{~kg}$ (P15 - P50)

b) General Condition: Patient appears in good general conditions, hydrated, afebrile to touch at the time of admission, capillary filling $<3 \mathrm{sec}$.

c) Head: Normocéfalo, without tumors or softenings.

d) Nose: Mesorrina, vestibules and permeable nasal slides, central septum, eutrophic turbinates, no evidence of rhinorrhea.

e) Mouth: symmetrical lips, moist oral mucosa, integral palate, central and mobile uvula, grade II / IV tonsils, nongranulomatous posterior pharyngeal wall.

f) Right ear: Normalized auricular pavement, permeable external auditory canal, intact tympanic membrane.

g) Left ear: increase of retroauricular volume, soft, without signs of flogosis, left external auditory canal stenotic, hyperemic, abundant greenish otorrhea, non-fetid, tympanic membrane not evaluable.

h) Neck: symmetrical, mobile, non-visible non-visible thyroid, palpable, movable, non-painful, lateritic lateral adenomegaly, smooth surface, hardy and well delimited edges of approximately $1.5 \mathrm{~cm}$.

i) Thorax: symmetrical, normoexpansible, respiratory sounds present in both hemithorax without aggregates.

j) Cardiovascular: Regular rhythmic heart sounds without blows.

k) Abdomen: Air fluid sounds present, soft, depressive, not painful, no visceromegalias are palpable.

l) Extremities: mobile, symmetrical, eutrophic. Muscular Strength: V / V.

m) Neurological: Conscious, oriented in three planes, irritable.

\section{Income Diagnostics: Otitis Media Supurative left ear.}

A. Temporal bone tumor Left in study: Histiocytosis of Langerhans A / D cells.

B. Work Plan: It was decided to hospitalize in our service and start treatment with Ceftriaxone at a dose of $75 \mathrm{mg} /$ $\mathrm{kg}$ / day order day, Quinoftal (drops) BID, Dexamethasone at 


\section{Global Journal of Otolaryngology}

$0.6 \mathrm{mg} / \mathrm{kg} /$ day TID for 3 days, profenid $2 \mathrm{mg} / \mathrm{kg} /$ dose TID, irtopan at $0.5 \mathrm{mg} / \mathrm{kg} /$ day in case of nausea and / or

vomiting, omeprazole at $1 \mathrm{mg} / \mathrm{kg} /$ day OD. Laboratories, functional study, and middle ear and mastoid tomography are requested.

Laboratories of Income (11/26/15) (Tables 1 \& 2).

Table 1: Complete Hematology.

\begin{tabular}{|c|c|c|c|c|c|c|c|c|}
\hline WBC & NE & LY & EO & HGB & HCT & VCM & HCM & PLT \\
\hline 14,6 & $82,8 \%$ & $8,6 \%$ & $1,8 \%$ & $9,0 \mathrm{~g} / \mathrm{dl}$ & $27,5 \%$ & $70,7 \mathrm{fL}$ & $23,1 \mathrm{pg}$ & 453.000 \\
\hline
\end{tabular}

Table 2: Blood chemistry.

\begin{tabular}{|c|c|c|c|c|c|c|c|c|c|c|}
\hline Glicemia & Urea & Creatinina & TGO & TGP & LDH & Bili T & Bili D & Prot. Total & Albúmina & Globulina \\
\hline $89 \mathrm{mg} / \mathrm{dl}$ & $19 \mathrm{mg} / \mathrm{dl}$ & $0,6 \mathrm{mg} / \mathrm{dl}$ & $10 \mathrm{U} / \mathrm{L}$ & $14 \mathrm{U} / \mathrm{L}$ & $184 \mathrm{U} / \mathrm{L}$ & $0,16 \mathrm{mg} / \mathrm{dl}$ & $0,06 \mathrm{mg} / \mathrm{dl}$ & $7,3 \mathrm{~g} / \mathrm{dl}$ & $4,3 \mathrm{~g} / \mathrm{dl}$ & $2,94 \mathrm{~g} / \mathrm{dl}$ \\
\hline
\end{tabular}

\section{a) Evolution}

i. 11/27/2014: Patient is reevaluated with an increase in the volume increase in the retroauricular region with the same characteristics as described above (soft without signs of floosis in the left mastoid region). In view of laboratory results, the diagnosis of hypochromic microcytic anemia is associated.

ii. 11/28/2014: Performed Functional Study: Tonal Audiometry where it is evidenced: Right Ear: Normal Hearing. Left ear: Moderate conductive hearing loss (Appendix 1).

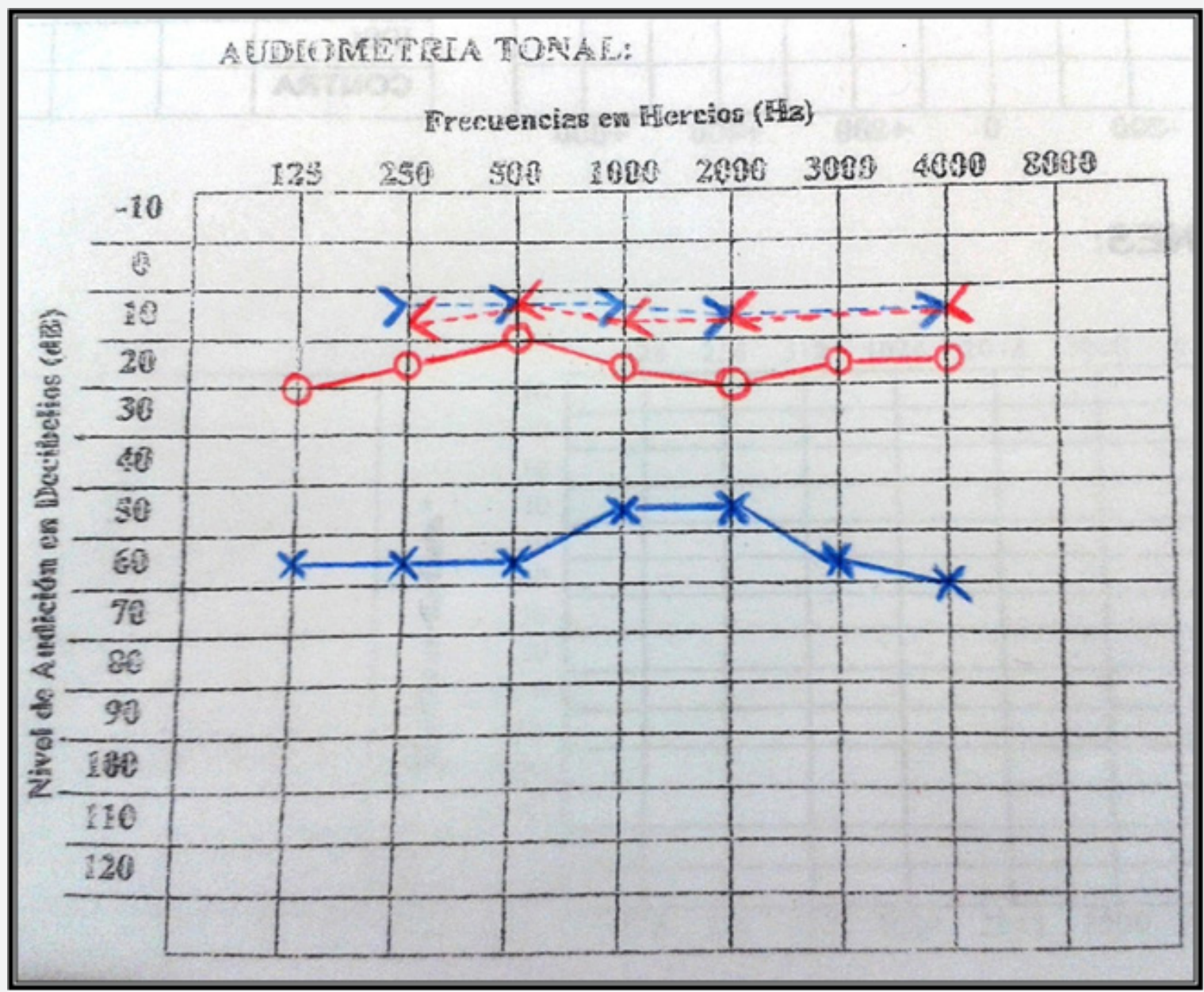

Appendix 1: Audiometría Tonal:

a) Average in dB. Conversational Frequencies (500 - 1000 - $2000-3000 \mathrm{~Hz}$ ) OD: $15 \mathrm{~dB}$ OI: $50 \mathrm{~dB}$

b) Percentage of Hearing Loss: OD: $0 \%$ OI: $37.5 \%$ Biaural: $6.25 \%$ 


\section{Global Journal of Otolaryngology}

iii. 01/12/2014: Due to the persistence of the clinic, Ceftriaxone is omitted and treatment with Cefepime at a dose of $150 \mathrm{mgs} / \mathrm{kg} /$ day and Clindamycin at a dose of 30 $\mathrm{mg} / \mathrm{kg} /$ day is given and received for 7 days. iv. 02/12/2014: In view of diagnostic presumption, an evaluation by the Oncology Service is requested, which suggests Abdominal Echo, Chest Tomography, Abdomen and Pelvis with double contrast and Bone Gammagram.

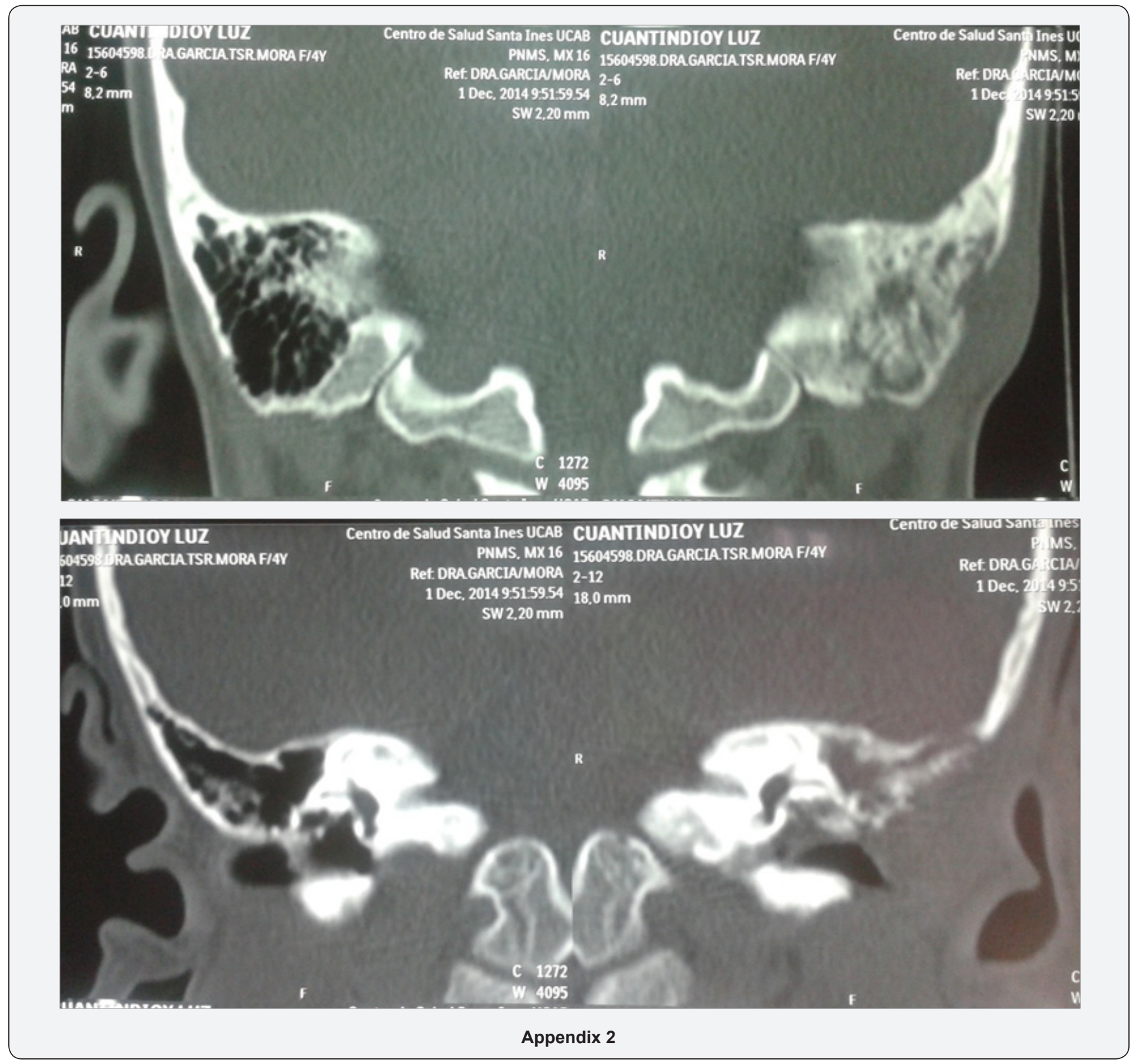

v. 03/12/2014: Tomography of the middle ear and mastoid is received: evidencing mastoid asymmetry, loss of the cortical mastoid of the left ear that impresses secondary to an erosive - infiltrative type process that compromises the superficial mastoid ipsilateral cells. Obliteration of the left external auditory canal at the expense of volume increase at the ceiling level, isodense characteristics, occupation of antrum, epitympanum and mesotympanum by soft tissue density, with preservation of ossicular elements and thickening of the left tympanic membrane (Appendix 2). vi. 10/12/2014: Patient persists with abundant otorrhea of the same characteristics as those described and intermittent hyperthermia of $39^{\circ} \mathrm{C}$, which is why reevaluation is requested by the infectology service, who suggests omitting previous antibiotic therapy and initiating Teicoplanin at doses of $10 \mathrm{mg} / \mathrm{Kg} /$ dose every 12 hours for three days and then order day and Meropenem at doses of $120 \mathrm{mg} / \mathrm{kg} /$ day every 8 hours.

vii. 12/12/2014: Thorax, Abdomenand Pelvis Tomography are present where: bilateral mediastinal and axillary 
lymphadenopathies that reach up to $20 \mathrm{~mm}$, no lesions of the pulmonary parenchyma, no parenchymal involvement of upper abdominal structures, bilateral inguinal adenopathies of Up to $12 \mathrm{~mm}$.

viii. 12/16/2014: The patient is taken to the operating room where tympanoplasty and left open mastoidectomy are performed with a biopsy. Surgical findings: whitish lesion, protruding cerebroid aspect in mastoid lateral wall with extension to the posterior wall and CAE roof, temporal scale, mastoid cells, antrum, epitympanum and mesotympanum with preservation of ossicular elements. Excision is performed.

ix. 18/12/2014: Anatomopathological report: Macroscopic description: The specimen consists of four irregular fragments of tissue, the largest measuring $1.3 \times 0.6 \times 0.4 \mathrm{~cm}$, brown, reddish, homogeneous, soft. They are included in their totality for histological study concluding:

b) Diagnosis: Chronic Granulomatous Otomastoiditis

i. 12/23/2014: It is evaluated by the Pneumology Service in view of anatomopathological results, mediastinal lymphadenopathy and epidemiological contact with maternal uncle with pulmonary tuberculosis one year ago. It is requested: PPD, BK and culture of gastric content, HIV.

ii. 12/26/2014: PPD reading is performed: $18 \mathrm{~mm}$ which is positive, $2 \mathrm{BK}$ of gastric contents and HIV: Negative.

iii. 28/12/2014: In view of the results, anti - tuberculosis treatment begins with: Rifampicin at a dose of $20 \mathrm{mg} / \mathrm{kg} /$ day, Isoniazid at doses of $15 \mathrm{mg} / \mathrm{kg} /$ day, Piperazinamide at doses of $20 \mathrm{mg} / \mathrm{kg} /$ day and ethambutol At a dose of $15 \mathrm{mg}$ / kg / day.

iv. 1/8/2015: Immunohistochemical study: Using the peroxidase-labeled secondary antibody conjugated dextran polymer using appropriate positive controls and antigen retrieval methods, the following antigens were investigated in the tumor: CD 68, CD 1a.

\section{Result:}

i. CD 68: Diffuse positive immuno-reaction in histiocytes.

ii. CD 1a: Negative immunization.

a) Diagnosis: Granulomatous Otomastoiditis:

NOTE: CD1a study was performed and no marker positive Langerhans cells were observed. Histology seems to correspond to a granuloma by an infectious agent; However, the stains for acid resistant fungi and acid bacillus were negative.

i. 09/01/2015: Maintained treatment with Teicoplanin at $10 \mathrm{mg} / \mathrm{kg} /$ day and meropenem at $120 \mathrm{mg} / \mathrm{kg} /$ day TID for 27 days and supervised antituberculosis treatment for 9 days. In view of satisfactory clinical evolution, medical discharge with outpatient antituberculosis treatment was decided.

ii. $\quad 01 / 20 / 15$ : It is valued by our consultation evidencing to the patient in stable general conditions. Denies otodynia, otorrhea and hyperthermia. At the physical examination: Left ear: Normally implanted auricular pavilion, there is no evidence of increased volume in the retroauricular region, postoperative scar without signs of flogosis. Permeable external auditory canal, tympanic membrane with cellular detritus on its surface. It remains receiving outpatient antituberculosis treatment.

iii. 02/19/15: Persist in good general conditions. Denies otodynia, otorrhea and hyperthermia. At physical examination: Left ear: Normally implanted auricle, without volume increase in the retroauricular region, unscathed postoperative scar. Pervious external auditory canal, tympanic membrane with few cellular detritus on its surface. Remain receiving outpatient antituberculosis treatment.

iv. 05/15/15: Remains in good general condition. Denies otodynia, otorrhea and hyperthermia. At physical examination: Left ear: Normally implanted auricle, without volume increase in the retroauricular region, unscathed postoperative scar. Permeable external auditory canal, tympanic membrane undamaged. Continue to receive outpatient tuberculosis treatment.

\section{Discussion}

In the pediatric population otitis media is a frequent reason for consultation. About $84 \%$ of children have at least one episode of otitis media during childhood [2]. Tuberculosis (TB) is one of the most studied infectious pathologies in the history of medicine, both in the past and in the present era, as this is a public health problem. During much of the twentieth century, its high incidence and mortality was disturbing. Currently, the emergence of strains resistant to anti-tuberculosis drugs, and the increase in the frequency of this disease in recent years, is what keeps health teams alert [7]. Although tuberculosis can affect any organ, only 15 to $25 \%$ of cases are extrapulmonary. These are much more common in immunosuppressed patients, in whom between 50 and $80 \%$ of the cases the involvement is extrapulmonary [8].

It is an entity that predominates in both developed and underdeveloped countries and has a predilection for the male sex, with a 3: 1 ratio. It usually affects young adults and early childhood [8]. Tuberculous otomastoiditis shows that it occurs more frequently in pediatric age, with up to $84 \%$ of cases reported in children under 15 years of age [8]. The bacilli penetrate the lungs carried by the aerosol droplets, where they are phagocytosed by the macrophages and transferred to the regional lymph nodes, where their diffusion is neutralized; Or reaching the bloodstream and disseminating widely. At the 
locations where plantings occur, monocytes are transformed into macrophages and histiocytes, and eventually form granulomas. Microorganisms remain alive within macrophages, but they do not spread any more, unless there is a reactivation [8].

In $95 \%$ of the cases; Tuberculosis, is caused by human Mycobacterium tuberculosis and the rest is divided between Mycobacterium bovis and atypical Mycobacteria. At 2 to 8 weeks of the primoinfection, the host creates a cellular hypersensitivity, which can be recognized by a skin test that measures the reaction to purified tuberculin protein derivative (PPD), a mixture of unpurified antigens [8,9]. As far as otorhinolaryngology is concerned, the most common form of extrapulmonary tuberculosis involving head and neck structures is cervical lymphadenitis, accounting for $95 \%$ of cases. This disease can also affect areas such as the middle ear, nasal cavity, oropharynx, nasopharynx, parotid and submandibular gland, esophagus, palate, tongue, trachea, larynx, thyroglossal canal and oral mucosa in which only $1 \%$ ) $[6,10]$.

Within this group, tuberculous otomastoiditis is a rare complication of pulmonary tuberculosis. However, it ranks second among the most frequent causes of extrapulmonary tuberculosis of otorhinolaryngological origin after laryngeal tuberculosis $[6,11]$. Chronic otitis media for tuberculosis was first described in 1853, and it was Eschle who in 1883 isolated the bacillus in optic secretion [12,13]. At the beginning of the 20 th century, 3 to $5 \%$ of chronic otitis media were produced by TB with $9.5 \%$ of them occurring in children under 5 [14].

Since then, the universal literature only mentions reports of isolated cases of tuberculous otitis media. Attempts to conduct major literature reviews, such as the Royal National Throat, Nose and Ear Hospital of England with 22 cases in a 30-year review [15], Grewald et al. [16] With 18 patients [16], Ukai And associated with 48 patients [17], Mojen and his group who; In 1992, performed a review of tuberculous otitis media throughout the century reporting only 320 patients [18] and more recently Nishiike et al. With seven cases [18] (in which the pathological mechanism was aspiration of bacilli through Eustachian tube), have served to highlight how little documented and underdiagnosed this disease is.

Tuberculous otitis media (OMT) is a very rare form of clinical presentation of $\mathrm{TB}$, whose incidence currently ranges from $0.05 \%$ to $0.9 \%$ of chronic otitis media $[12,14]$. In most cases tuberculous Mycobacterium is the causative agent, infections secondary to atypical mycobacteria such as Mycobacterium avium and Mycobacterium fortuitum may occur occasionally [19]. The decline in this clinical form of TB is due to several factors, such as: progress in the area of public health, Calmette Guerin bacillus vaccine, availability of anti-TB drugs and improvement of quality of life [13]. On the other hand, since the signs and symptoms of tuberculous otitis media are difficult to differentiate from chronic otitis media caused by other agents, and that the frequency of this pathology has declined, there has been a significant decrease in clinical suspicion, With the risk of a late diagnosis with the implications and complications that this entails. By way of example, one can cite hearing loss, which may become permanent $[11,20]$.

During the last years; In spite of a decrease in its incidence, an increase of cases has been observed worldwide. This is due to different causes, some of them being the AIDS epidemic, increasing migrations from endemic areas, overcrowding in different geographical areas, and partial control of the administration of medicines by health authorities $[12,20]$. In a patient with chronic otitis media, a suspicion of OMT should always be maintained, especially if antibiotic treatment fails, if it has had any contact with TB, or if it has pulmonary or extrapulmonary TB. The latter association is observed between $40 \%$ and $65 \%$ of the cases $[12,14]$.

Infection of the middle ear by the tuberculous bacillus may be primary or secondary [11]. In the pediatric population, the most frequent form of clinical presentation is that of the primary complex $[11,19]$. The possible routes of transmission are diverse, but the most frequent is the hematogenous secondary to a miliary TBC in which a primary infection would occur with later cantonment of the bacilli in the middle ear with its subsequent reactivation. Other possible routes are those that occur directly, ie from the nasopharynx through the Eustachian tube especially in chronic expectorants or by the regurgitation of unpasteurized milk especially in infants and malnourished, by lymphatic extension. Direct inoculation to the external ear has also been mentioned through tympanic perforation, by direct extension to adjacent structures, such as the central nervous system, and by congenital infection, either by placental route or by the placental canal especially In mothers with urogenital TB [7,8,12,21,22].

Tuberculosis of the middle ear; With no other apparent tuberculous focus, occurs primarily in the pediatric population following the intake of unpasteurized milk, where the bacillus would reach the ear through the external auditory canal or the eustachian tube. While tuberculosis of the middle ear occurs mostly in adults, in whom infection of the middle ear by hematogenous dissemination or contamination of the nasal cavities and Eustachian tube is evidenced from contaminated sputum from a distant, usually pulmonary $[11,14,23]$.

\section{Lederer describes three types of tuberculous otomastoiditis:}

a) Miliar form, begins as a tuberculosis in the submucosa of the middle ear and subsequently involves the periosteum and the bone.

b) Granulomatous form: manifests as a circumscribed granuloma or as a proliferative lesion involving the bone.

c) Caseous form, showing tuberculous formations, caseification and sometimes necrosis and bone sequestration (Lederer 1973) [23]. 
With respect to the clinic, the classic triad described since the discovery of tuberculous otitis media has been painless otorrhea, tympanic perforation and facial paralysis. It is necessary to emphasize that at present it is presented in a more heterogeneous form, characterized by a slow and insidious evolution of serous otorrhea, which may become purulent by bacterial superinfection, with or without otalgia, and hearing loss at diagnosis $[13,20,24]$. It is usually unilateral [25]. Hyperthermia is uncommon in uncomplicated cases and otalgia is associated with bacterial superinfection $[25,26]$.

Otorrhea, unlike suppurative otitis media, does not occur due to the accumulated tension at the retrotimpanic level, but rather due to the granulations formed on the areas of the tympanic membrane as a result of the tuberculous process [25]. Physical examination; In otoscopy, it is possible to confirm serous or purulent otorrhea from the middle ear which may have weeks or years of evolution, with signs suggestive of CBT infection: thick and hyperemic tympanic membrane, single broad or multiple tympanic perforation (typically tend To coalesce forming a large central perforation) as a result of caseous necrosis [25], the mucosa of the middle ear case looks pale or pink with granulation tissue or granulomas are evident in the external auditory canal, destruction of the ossicles Can sometimes be observed through the perforated tympanic membrane, erosion of the cortical mastoid bone and involvement of the facial nerve sheath. Lymphadenopathy can be found in the periauricular region [8].

Active TB is diagnosed by demonstrating the microorganisms in the sputum, tissues or body fluids, by direct examination (Ziehl-Neelsen technique or fluorescent auramine-rhodamine staining) or culture, either with the classical Löwestein-Jensen technique Which takes 4 to 8 weeks to be isolated or using more modern techniques for rapid diagnosis, such as molecular biology (polymerase chain reaction) or high quality liquid chromatography [8]. Radiometric techniques allow it to grow in 1 to 2 weeks, but more time is needed for its identification [8]. However, even the aetiological confirmation of TBC for OMT poses a challenge. Mycobacterial direct observation tests have poor performance [23].

First, in children infected with Koch's bacilli, the bacillary population is minimal, so they usually have negative sputum smear and gastric aspirate. Second, as in other extrapulmonary forms, the middle ear has a low concentration of bacilli, and in addition the frequent use of optical drops with neomycin (weakly antituberculous) [27], or other antibiotics, results in bacteriological analyzes of secretions and histological tissue of Low yield $[14,24,28]$. Third, the characteristics of the slow growth of this agent, and the interference of its development by other varieties of bacteria, make the probability of sputum smear microscopy and positive culture in optic secretion less than $20 \%$ and between 5 and $35 \%$ respectively $[12,20,21]$.
A positive skin test may be helpful, but a negative result does not exclude tuberculosis. As for its interpretation; Tuberculin test (PPD) can be reported as: 0-4 mm (negative or non-reactive), 5-9 $\mathrm{mm}$ (weakly reactive) that can be seen in tuberculosis infections by atypical mycobacteria or secondary to a response generated by immunization with BCG and $10 \mathrm{~mm}$ or more (positive or reactive) that may be seen in active infection by the tuberculous bacillus or in response to non-immunized patients. The observation of the acid-fast bacillus in Ziehl-Neelsen staining in the ear fluid is a strong predictor of tuberculosis [9,26-29].

The imaging is fundamental, since it not only allows orienting itself to a diagnosis, but also it can show possible complications. A normal chest $\mathrm{x}$-ray does not exclude the diagnosis of tuberculosis [23]. The method of choice is computed tomography, where the opacification of the middle ear and mastoid, sclerosis of the mastoid cortex, increased density and radiolucency of the mastoid cortex can be objectified if there is bone resorption, destruction of ossicles and mastoid bone destruction or Petrous bone $[28,30]$. Likewise, a CT scan helps us to rule out chronic granulomatous otitis media $[8,31,32]$.

On the other hand, the pathological anatomy plays a primordial role in relation to the etiological diagnosis of this disease. A concordant histology with a TBC infection, with a granulomatous tissue with epitheloid cells and giant cells of Langhans with caseous and necrotic areas, together with a clinical suspicion, are sufficient to confirm the diagnosis, independently of the results of the cultures, taking into account Account the poor performance of these. Another alternative available for diagnosis is the polymerase chain reaction (PCR) technique for the genetic analysis of the bacillus in optic secretion or tissue biopsy, with a high sensitivity and specificity. However, a negative result does not rule out TBC infection [7]. In formulating the diagnosis of all chronic otitis media should be kept in mind; And discard as possible causes, fungal infection, cholesteatoma, histiocytosis, Wegener's granulomatosis, eosinophilic granulomatosis, syphilis and sarcoidosis [20,24,31,33].

The criteria for the diagnosis of tuberculous otitis media are: chronic otitis media that does not respond to conventional treatment with oral or parenteral antibiotics, presence of large granulation tissue in the middle ear, facial paralysis, history of pulmonary tuberculosis, Tuberculin test (PPD) and regional lymphadenitis. The presence of three of these criteria establishes the diagnostic suspicion, whereas with five or more of these criteria the diagnosis is considered [10]. The presence of casein granulomas should make us suspect infection with mycobacteria and establish tuberculostatic treatment with the objective of avoiding progression to the central nervous system and permanent auditory sequelae $[23,34]$. Complications of tuberculous otitis media are numerous. Its reversibility, and the severity of its sequelae, are directly related to the time of initiation of treatment, which reinforces once again the importance of a suspicion and an early diagnosis [25]. 
The most frequent of these complications is hearing loss, occurring in $90 \%$ of cases. This can be conductive type in $90 \%$ due to tympanic perforation and destruction of the ossicles chain, sensorineural in $8 \%$ with healthy tympanum related to fistulas of the optical capsule at promontory level, and mixed in $2 \%[21,23-25,35]$. Patients may also have facial paralysis and other cranial nerve palsies. Facial paralysis in the context of chronic non-cholesteatomatous otitis media should lead to suspicion of tuberculous etiology $[23,27]$. This is produced by compression or by infiltration of its sheath. It is observed in $16 \%$ up to $35 \%$ of cases and is reversible. Other complications include labyrinthitis, ossicular chain necrosis, otomastoiditis, bone sequestration and destruction of the mastoid, and petrous bone, retroauricular fistula, and temporo-mandibular joint involvement. Among intracranial complications it is important to mention: meningitis, tuberculoma, cerebral abscesses, multiple cranial nerve palsies, labyrinthitis, and lateral thrombosis of the sigmoid sinus [13,20,23,27,25].

The treatment of this entity can be medical or surgical. However, most of the literature mentions that the treatment is medical, with good results, and that a multidrug regimen should be used for periods of not less than 6 months. The indicated antibiotic scheme is the simplified primary of TB for pulmonary or extrapulmonary forms, consisting of a daily phase of isoniazid, rifampicin and pyrazinamide for 50 doses, and a biweekly phase of isoniazid and rifampicin for 32 doses. The association with corticosteroids has been used in some cases for the management of granulations, control of the fibrotic scarring process, and treatment of intracranial complications and facial paralysis [35].

After successful medical treatment, surgery may be considered; Especially in those cases of patients who suffered prolonged clinical signs before starting effective treatment. Surgical exploration offers the ideal opportunity to make a histological diagnosis [11]. Necrotic tissue can be removed through a mastoidectomy [36]. Surgery is also indicated for the resolution of those cases with subperiosteal abscesses, bone sequestration and facial paralysis or paralysis of other reversible cranial nerves [23]. It is incorrect to suppose that all cases of tuberculous otitis media should have a protracted evolution or that a diagnostic presumption can not be made prior to extensive destruction of the bone. However, for this to be possible, the index of diagnostic suspicion should be raised especially in any prolonged middle ear infection that does not respond to the usual management and in those patients from countries where the disease is endemic [11,23].

Early diagnosis of aural tuberculosis is of considerable practical importance. Tuberculosis is a curable disease. Timely and early treatment will prevent the loss of potentially normal hearing as well as the development of serious neurological complications [11,37-40]. Although tuberculous otomastoiditis is a rare manifestation of extrapulmonary tuberculosis, it should always be considered in cases of persistent otitis media or refractory to conventional treatment. There are typical clinical characteristics that are not exclusive to tuberculosis otomastoiditis, so the basis of the diagnosis is a well-founded suspicion. Thus we can show that in our case the clinic focuses on an abundant, non-feted otorrhea accompanied by otodynia, hyperthermia and moderate left conductive hearing loss. There was no evidence of involvement of the facial nerve. In addition, it is worth noting that the biochemical tests performed to detect the presence of the tuberculous bacillus were negative and that the definitive diagnosis was made postoperatively after the processing of the material sent to biopsy and the result of the PPD, obtaining; Once the antituberculous treatment has started, a satisfactory evolution of the clinical picture that allows the discharge of the patient with outpatient follow-up.

\section{Conclusion}

Otitis is a public health problem of great importance in Venezuela that warrants a rigorous and permanent epidemiological surveillance. Doctors and the Venezuelan health system have all the resources for their primary, secondary and tertiary prevention to significantly reduce the frequency, complications and sequelae of these infections. The primary prevention is through immunizations, since the prevention of viral infections (influenza, measles, rubella, mumps) and bacterial infections (Haemophilus influenzae type b, pneumococcus, meningococcus) is avoided.

Tuberculosis is a pathology that has evolved along with advances in medicine since the last century. If it has very high incidences to face the resistance in its treatment, the world public health has had to adapt to new challenges to control it. Tuberculous chronic otitis media is a very unusual form of presentation. The clinical presentation is variable, the multiple perforations that previously were characteristic features are no longer seen so frequently. At present the typical characteristic of the disease is a painless, profuse, non-fetid otorrhea that does not respond to topical or systemic antibiotic treatment. It is often accompanied by disproportionate hearing loss compared to clinical findings and in most cases exuberant pale granulations are evident.

At the moment it is considered an entity of difficult diagnosis by several factors:

a) The index of suspicion is very low as they occur in less than $0.9 \%$ of the cases of otitis media reason why it is often not considered in the differential diagnosis;

b) The clinical signs are variable and do not usually coincide with the classic descriptions;

c) It is not usually associated with pulmonary involvement;

d) False negatives in the culture are very frequent because of the nature of the Mycobacteria and because other pathogens interfere in its growth. Therefore, the diagnosis is usually made postoperatively in many cases. 
Complications are significantly greater than those occurring in the context of chronic suppurative otitis media or chronic non-cholesteatomatous otitis including: hearing loss that may be permanent, labyrinthitis, facial paralysis, ossicular chain necrosis, otomastoiditis, abduction And bone destruction of the mastoid, and of petrous bone, retroauricular fistula, temporomandibular joint involvement, and lateral thrombosis of the sigmoid sinus, among others. It is for this reason that this etiology should be suspected in any case of otitis that does not respond to the usual antibiotic treatment, or that presents as non-painful otorrhea. The test of P.P.D. Routinely. Performing an early diagnosis is vital, as; The earlier antituberculosis treatment begins, the fewer complications. This review aims to raise in the medical community a concern about this condition, since at present, Koch's bacillus infection is increasing worldwide, so that every professional should be attentive and prepared to perform a complete Differential diagnosis.

\section{References}

1. Garrido Elizabeth, Suárez José Antonio, Valera Rodolfo (2013) Otitis. Venezuelan Consensus on Otorhinolaryngology Infections, Caracas, Venezuela, 33-51.

2. Allan S Lieberthal, Aaron E Carroll, Tasnee Chonmaitree, Theodore G Ganiats, Alejandro Hoberman, et al. (2013) The Diagnosis and Management of Acute Otitis Media. Pediatrics 131(3): 1-38.

3. Monasta L, Ronfani L, Marchetti F, Montico M, Vecchi Brumatti L, et al. (2012) Burden of disease caused by otitis media: systematic review and global estimates. PLoS One 7(4): e36226.

4. Maurera Peña Eukaris D, Reyes Herrera Yajana, Guerrero Guerrero Juan M, Herde Rodríguez José D, Figuera Jaspe Daniela, et al. (2011) Mycobacterium tuberculosis infection: casuistry of the Interna Medicine III service of the Hospital Vargas de Caracas. Med Interna 27(4): 275-279.

5. Rebolledo P Vilma E, Rebolledo P Kirbeliz E (2011) Extrapulmonary tuberculosis in two infrequent sites. The purpose of three clinical cases. Salus 15(2).

6. Dera Flores Milanyela, Fuentes Moreno Dianora, Ruíz Carmen, Married Mario (2002) Laryngeal tuberculosis: on the subject of a case. Arch Venez Pueric Pediatr 65(1): 37-39

7. Nishiike S, Irifune M, Doi K, Osaki Y, Kiuchi N (2003) Tuberculous otitis media: clinical aspect of 12 cases. Ann Otol Rhinol Laryngol 12: 935938.

8. Marín Garrido C, Gómez Díaz C, Martínez-Berganza R, Sampériz L Carmen, et al. (2000) Otitis media tuberculous. ORL Aragón 3(2): 2022.

9. Fernández de Larrea Carlos, Fandiño Fecil, López Diana, Del Nogal Berenice, Rodríguez Nilia, et al. (2002) Tuberculosis in children under 15 years of age in the Warao population of Venezuela. Invest Clin 43(1): 35-48.

10. Sousa Renato, Siqueira Briglia Maria Francisca, Nadaf de Lima Luiz Carlos, Siqueira de Carvalho Rafael, Martins Texeira Lívio, et al. (2010) Frequency of Otorhinolaryngologies' Manifestations in Patients with Pulmonary Tuberculosis. Intl Arch Otorhinolaryngol 14(2): 156-162.

11. Sean L. Sellars and Allan B. Serd (1973) Aural Tuberculosis in Childhood. SA Medical Journal, Department of Otolaryngology, Groote Schuur Hospital, Cape Town, South Africa, 47: 216.

12. Awan MS, Salahuddin I (2002) Tuberculous otitis media: two case reports and literature review. Ear Nose Throat J 81(11): 792-794.
13. Chirch LM, Ahmad K, Spinner W, Jimenez VE, Donelan SV, et al. (2005) Tuberculous otitis media: report of 2 cases on Long Island, NY, and a review of all cases reported in the United States since 1990 Through 2003. Ear Nose Throat J 84(8): 488-497.

14. Herrera E, Contreras R, Vargas A (2007) Optic tuberculosis: case report and bibliographic review. An Orl Mex 52: 39-43.

15. Kirsch CM, Wehner JH, Jensen WA, Kagawa FT, Campagna AC (1995) Tuberculous otitis media. South Med J 88(3): 363-366.

16. DS Grewal, B Baser, RN Shahani, S Khanna (1991) Tuberculous otitis media presenting as complications; Report of 18 cases. Auris Nasus Larynx 18(3): 199-208.

17. Ukai K, Sakakura Y, Yoshii S, Majima Y, Taniguchi T, et al. (1979) Fortyeight cases of tuberculous otitis media. Nippon Jibiinkoka Gakkai Kaiho 82(6): 554-560.

18. Nishiike S, Irifune M, Kubo T (2000) Seven cases of tuberculous otitis media. Nippon Jibiinkoka Gakkai Kaiho 103(12): 1263-1271.

19. Nadol Joseph B, Merchant Saumil N Chapter 163: Systemic Disease Manifestations in the Middle Ear and Temporal Bone. Cummings Otolaryngology: Head and Neck Surgery 2011, (6 ${ }^{\text {th }}$ edn). Editorial Mosby 1 - 18.

20. Sens PM, Almeida CI, Valle LO, Costa LH, Angeli ML (2008) Tuberculosis of the ear, a professional disease. Braz J Otorhinolaryngol 74(4): 621627.

21. Pedro Vaamonde, Crisanto Castro, Nicolas García-Soto, Torcuato Labella, Ascensión Lozano (2004) Tuberculosis otitis media: A significant diagnostic challenge. Head and Neck Surgery 130(6): 759766.

22. Mongkolrattanothai K, Oram R, Redleaf M, Bova J, Englund JA (2003) Tuberculosis otitis media with mastoiditis and central nervous system involvement. Pediatr Infect Dis J 22(5): 453-456.

23. YU Kelgaonkar, Shaila Bangad, Sham S Somani, Surabhi Chopra, Sachin B Ingle (2012) Tuberculosis of Mastoid bone-case report. Indian Journal of Medical Case Reports 1(1): 30-32.

24. Vital V, Printza A, Zaraboukas T (2002) Tuberculous otitis media: a difficult diagnosis and report of four cases. Pathol Res Pract 198(1): 31-35.

25. Akanksha A Saberwal, Haritosh K Velankar, Yogesh G Dabholkar, Adip K Shetty, Devayani Shinde (2013) Tuberculous otitis media - revisited with 3 interesting case reports. Journal of Evolution of Medical and Dental Sciences 2(49): 9436-9440.

26. Marlowe FI (1972) Primary Tuberculous Otomastoiditis. Ann Otol Rhinol Laryngol 81(2): 288-290.

27. González Pena Miriam, Blanc M Josep, Brown Jesus (2011) It occurs as the first manifestation of tuberculosis. Clinical Medicine 136(6): 268269.

28. MH Rho, DW Kim, SS Kim, YS Sung, IS Kwon, et al. (2007) Tuberculous Otomastoiditis on High-Resolution Temporal Bone CT: Comparison with Nontuberculous Otomastoiditis with and without Cholesteatoma. Am J Neuroradiol 28(3): 493-496.

29. Sahn SA, Davidson PT (1974) Mycobacterium tuberculosis infection of the middle ear. Chest 66(1): 104-106.

30. Munoz A, Ruiz-Contreras J, Jimenez A, Maté I, Calvo M, et al. (2009) Bilateral Tuberculous otomastoiditis in an immuno-competent 5-yearold child: CT and MRI findings. Eur Radiol 19(6): 1560-1563.

31. Nitin Gupta, Arjun Dass, Neha Goel, Sandeep Tiwari (2015) Tuberculous Otitis Media Leading to Sequentialib Bilateral Facial Nerve Paralysis. Iranian Journal of Otorhinolaryngology 27(3): 80.

32. Kunal M Patel, Abdulrahman Almutairi, Mahmood F Mafee (2014) 


\section{Global Journal of Otolaryngology}

Acute otomastoiditis and its complications: Role of imaging. Operative Techniques in Otolaryngology 25(1): 21-28.

33. Bhalla RK, Jones TM, Rothburn MM, Swift AC (2001) Tuberculous otitis media to diagnostic dilemma. Auris Nasus Larynx 28(3): 241-243.

34. Araújo Mercêdes Fabiana, Gonçalves Pinheiro Thaís, Teixeira Raymundo Igor, Rocha Soares Vítor Yamashiro, Machado Araújo Pedro Ivo, et al. (2011) Tuberculous Otitis Media Int Otol 7(3): 413-417.

35. Paredes W, Alejandro (2001) Tuberculosis in Otorhinolaryngology. Rev otolaryngolary cir cir-neck 61(4): 87-94.

36. Kollar D (1952) Primary healing of tuberculous otitis media on combined operative and streptomycin therapy. Acta Otolaryngol 42(45): 399-403.
37. Dagan R (2010) Appropiate Treatment of Acute Otitis Media in the Era of Antibiotic Resistance. Paediatr Drugs 12(1): 3-9.

38. Jensona H, Robert S (2004) Impact of Pneumococcal and Influenza Vaccines on Otitis Media. Current Opinion in Pediatrics 16(1): 58-60.

39. Pérez Porcunaa TM, Díaz Conradia A, Tobeña Boadaa L, Cuchí Burgosc E, Amilibia Cabezad E et al. (2006) Tuberculous oomastoiditis in a patient of Maghreb origin. Anales de Pediatría 64 (1): 100-108.

40. Lahoz Zamarro MT, Fernández Alamán A, Ortiz Domínguez L, Mirallas Mezquita M (2013) Tuberculosis of Head and Neck: Our Experience. ORL Aragón 16(1): 13-16.

\section{Your next submission with Juniper Publishers} will reach you the below assets

- Quality Editorial service

- Swift Peer Review

- Reprints availability

- E-prints Service

- Manuscript Podcast for convenient understanding

- Global attainment for your research

- Manuscript accessibility in different formats

( Pdf, E-pub, Full Text, Audio)

- Unceasing customer service

Track the below URL for one-step submission https://juniperpublishers.com/online-submission.php 